\title{
Actividad in vitro de los extractos etanólicos de Lantana camara L., Petiveria alliacea $L$. y Lippia dulcis T. frente a bacterias patógenas
}

In vitro activity of the ethanolic extracts from Lantana camara L., Petiveria alliacea L. and Lippia dulcis T. against pathogenic bacteria

Nahir Alejandra Navarrete Barragán ${ }^{1}$, Erika Fadime Pita-Ospina ${ }^{2}$, Ruth Mélida Sánchez Mora ${ }^{3}$, Sara Emilia Giraldo Quintero ${ }^{4}$, María Consuelo Bernal Lizarazú ${ }^{5}$

\section{Resumen}

Introducción. La biodiversidad colombiana y los saberes tradicionales permiten la exploración de plantas medicinales con potencial actividad antimicrobiana que podrían usarse para tratamiento de infecciones. Objetivos. Determinar la actividad antibacteriana de extractos etanólicos de Lantana camara L., Petiveria alliacea L. y Lippia dulcis T. sobre Pseudomonas aeruginosa ATCC 9027, Escherichia coli ATCC 25922, Proteus vulgaris ATCC 6380 y Staphylococcus aureus ATCC 25923. Materiales y métodos. Se realizó la adquisición del material vegetal y caracterización botánica, se obtuvieron los extractos etanólicos por percolación y se realizó caracterización fitoquímica preliminar mediante cromatografía en capa delgada (CCD). Se evaluó la actividad antibacteriana, mediante pruebas de difusión con disco y difusión en agar en concentraciones de $1 \mathrm{mg} / \mathrm{mL}$ y $2 \mathrm{mg} / \mathrm{mL}$; para extractos activos se estableció la Concentración Inhibitoria mínima (CIM) y Concentración Mínima Bactericida (CMB). Para análisis estadístico se realizó prueba t de Student. Resultados y discusión. Staphylococcus aureus ATCC 25923 fue sensible con Lantana camara L. y Lippia dulcis T. siendo este último activo también sobre Proteus vulgaris ATCC 6380 con efecto inhibitorio superior al 50\%. El extracto de Lippia dulcis T. presentó la mayor actividad

\footnotetext{
1. Bacterióloga, Universidad de Pernambuco.

ORCID: https://orcid.org/0000-0002-8336-9764

2. Bacterióloga, Universidad Colegio Mayor de Cundinamarca. ORCID: https://orcid.org/0000-0002-9042-2586

3. Bacterióloga, M.Sc genética, Ph.D Ciencias. Universidad Colegio Mayor de Cundinamarca ORCID: https://orcid.org/0000-0002-0572-8418

4. Química Farmacéutica, Ph.D. Ciencias Farmacéuticas. Universidad Nacional Abierta y a Distancia. ORCID: https://orcid.org/0000-0001-6652-8869

5. Médica, Bacterióloga. M.Sc Microbiología, Mg Salud pública y desarrollo social. Docente Universidad Nacional Abierta y a Distancia. ORCID: http://orcid.org/0000-0002-9049-1629

Correspondencia: maria.bernal@unad.edu.co
} 
inhibitoria sobre $S$. aureus (CMI: $1,95 \mathrm{mg} / \mathrm{mL}$ ). Ningún extracto mostró actividad sobre Escherichia coli ni Pseudomonas aeruginosa. Metabolitos secundarios, especialmente terpenoides y cumarinas fueron detectados en L. dulcis. Conclusiones. El estudio muestra que productos naturales derivados de plantas medicinales como los extractos etanólicos de Lantana camara y Lippia dulcis, presentan actividad antibacteriana sobre $S$. aureus y $P$. vulgaris y podrían ser alternativa promisoria para tratamiento de infecciones bacterianas.

Palabras claves: Etnofarmacología, extractos vegetales, antimicrobianos, antibacterianos, plantas medicinales, biodiversidad.

\section{Abstract}

Introduction. Colombian biodiversity and traditional knowledge allow the exploration of medicinal plants with potential antimicrobial activity, which could be used to treat infections. Objectives. To determine the antibacterial activity of ethanolic extracts of Lantana camara L., Petiveria alliacea L. and Lippia dulcis T. on Pseudomonas aeruginosa ATCC 9027, Escherichia coli ATCC 25922, Proteus vulgaris ATCC 6380 and Staphylococcus aureus ATCC 25923. Materials and methods. Performed the acquisition of plant material and botanical characterization, ethanolic extracts were obtained by percolation and preliminary phytochemical characterization was performed by thin layer chromatography (CCD). The antibacterial activity was evaluated by disc diffusion and agar diffusion tests at concentrations of $1 \mathrm{mg} / \mathrm{mL}$ and $2 \mathrm{mg} / \mathrm{mL}$; for active extracts, the Minimum Inhibitory Concentration (MIC) and Minimum Bactericidal Concentration (CMB) were established. For statistical analysis, Student's t test was performed. Results and discussion. Staphylococcus aureus ATCC 25923 was sensitive with Lantana camara L. and Lippia dulcis T. The latter being also active on Proteus vulgaris ATCC 6380 with inhibitory effect higher than $50 \%$. The extract of Lippia dulcis $T$. had the highest inhibitory activity on S. aureus (MIC: $1.95 \mathrm{mg} / \mathrm{mL}$ ). No extract showed activity on Escherichia coli and Pseudomonas aeruginosa. Secondary metabolites, especially terpenoids and coumarins were detected in L. dulcis. Conclusions. The study shows that natural products derived from medicinal plants such as the ethanolic extracts of Lantana camara and Lippia dulcis have antibacterial activity on $S$. aureus and $P$. vulgaris and could be a promising alternative for the treatment of bacterial infections.

Keywords: Ethnopharmacology, Plant Extracts, Anti-Infective Agents, Anti-Bacterial Agents, Medicinal Plants, Biodiversity. 


\section{Introducción}

Las enfermedades infecciosas son consideradas un importante problema de salud pública, debido a que representan altas tasas de morbilidad y mortalidad, y están relacionadas con fenómenos subyacentes como el inadecuado saneamiento básico y la emergente resistencia a los antimicrobianos (1). De acuerdo con la Organización Mundial de la Salud (OMS), las enfermedades infecciosas y parasitarias causaron durante el año 2015, 5.7 millones de defunciones a nivel mundial y más de 195.000 muertes en la región de las Américas (2).

Los antibióticos son una herramienta fundamental para combatir las enfermedades infecciosas, y desde su aparición han permitido disminuir la morbimortalidad asociada a estas patologías de forma significativa (3). A pesar de que la terapia antimicrobiana ocupa un lugar prominente en los avances de las ciencias médicas, se destaca la inminente y progresiva capacidad de los microorganismos para desarrollar resistencia a los diferentes agentes antimicrobianos (4). Los antibióticos se consideran recursos sanitarios no renovables, ya que el ritmo de crecimiento de la resistencia sobrepasa al de la incorporación de nuevas familias de antibióticos (5-6). Sin embargo, es posible investigar y desarrollar nuevas alternativas de tratamiento para las enfermedades infecciosas, dentro de las cuales se encuentran los productos naturales.
La OMS estima que cerca del $80 \%$ de la población en países en vía de desarrollo (especialmente del continente africano), utiliza la medicina tradicional (MT) para satisfacer sus necesidades primarias en salud y que cuando la MT emplea tratamientos, incluye el uso de medicinas a base de hierbas, partes de animales y/o minerales. Adicionalmente, la OMS reporta que en Colombia un $40 \%$ de la población utiliza la medicina tradicional (7). Colombia se encuentra catalogada como uno de los 14 países que alberga el mayor índice de biodiversidad en la tierra (8). Se estima que el territorio colombiano alberga aproximadamente 27,860 especies de plantas, de las cuales 2,400 son catalogadas como plantas medicinales (9).

La riqueza cultural y natural del territorio colombiano ha conducido a la realización de diversos estudios etnobotánicos enfocados en la descripción del uso tradicional de plantas medicinales para el tratamiento de enfermedades infecciosas. Dentro de los estudios sobre plantas medicinales cabe mencionar los realizados por Ruiters y cols. en África (10), Pinheiro y cols. en Brasil (11) y Savithramma y cols. en India (12). Referente a estudios sobre el uso de plantas medicinales en mercados populares en Colombia, se resalta el de Giraldo y cols. (13).

La familia Verbenaceae a la cual pertenecen plantas como Lantana cámara y Lippia dul- 
cis, comprende alrededor de 35 géneros y 1000 especies distribuidas principalmente en los trópicos y subtrópicos (14). Son ampliamente usadas en la medicina tradicional de diferentes países para el tratamiento de enfermedades parasitarias y trastornos respiratorios e inflamatorios. También se les han atribuido propiedades antimicrobianas, las cuales están directamente relacionadas con su amplia composición fitoquímica (15). Por su parte, Petiveria alliacea, se distribuye por lo general en regiones tropicales de América, como Centroamérica, las islas del Caribe, la selva Amazónica, México, Brasil, Colombia y Argentina, así como en regiones específicas de África. En la medicina tradicional se resaltan diferentes usos, entre ellos como diurético, antiespasmódico, analgésico, antiinflamatorio, antihelmíntico y para desordenes del sistema nervioso central. Dentro de sus propiedades antimicrobianas etnobotánicas se resaltan para infecciones cutáneas, urinarias, venéreas y del tracto respiratorio, además antifúngicas y antisépticas (16). Diferentes compuestos activos se han reportado; sin embargo, su composición es variable dependiendo del lugar y época de recolección y de la parte del material de donde se han aislado. Se resaltan petiverina A y petiverina B (diasteroisómeros del sulfóxido de S-bencil-cisteína), los cuales se encuentran en alta proporción en las raíces en comparación con las hojas y los tallos. En las raíces la actividad de la enzima sulfóxido de cisteína liasa sobre las petiverinas promueve mediante la formación de diferentes intermediarios la formación de compuestos trisulfuro (bencil-hi- droxi-etil-trisulfuro, dibencil trisulfuro) a los cuales se les han atribuido propiedades antimicrobianas (17).

Bajo este contexto, se han realizado diversos estudios orientados a la búsqueda de plantas medicinales de interés fitoquímico y farmacológico que pueden presentar actividad antimicrobiana sobre patógenos de interés en salud pública, tal como la evaluación de la actividad in vitro de extractos vegetales frente a bacterias Gram negativas y Gram positivas procedentes de aislamientos clínicos y Cepas Multidrogoresistentes (MDR) implicadas en infecciones del tracto urinario como los realizados por Mishra y cols. (18) y Marasini y cols (19) y la investigación de Ulloa y cols (20) sobre la actividad antimicrobiana de plantas nativas peruanas frente a Pseudomonas aeruginosa, encontrando resultados prometedores.

Recientemente han sido publicadas investigaciones relacionadas con las plantas de interés del presente estudio, dentro de las cuales cabe destacar la de Ochoa y cols. (21), donde extractos obtenidos a partir de hojas secas y frescas de Petiveria alliacea L. demostraron actividad antibacteriana sobre Escherichia coli, Staphylococcus aureus, Enterococcus faecalis y Pseudomonas aeruginosa. Por otra parte, Naz y Bano (22) reportaron que el extracto metanólico de hojas de Lantana camara L. presentó la máxima actividad antibacteriana frente a Staphylococcus aureus y Pseudomonas aeruginosa. Por su parte, Regnier y cols. (23) 
establecieron que aceites esenciales de Lippia escaberrima causaron la inhibición del crecimiento micelial y actividad fungistática.

El presente estudio se realizó con el fin de contribuir a la búsqueda de sustancias de origen natural como alternativa para el tratamiento de las enfermedades infecciosas, evaluando la potencial actividad antibacteriana de extractos etanólicos obtenidos de Lantana camara L., Petiveria alliacea L. y Lippia dulcis T. sobre las bacterias Pseudomonas aeruginosa ATCC 9027, Escherichia coli ATCC 25922, Proteus vulgaris ATCC 6380 y Staphylococcus aureus ATCC 25923.

\section{Materiales y métodos}

\section{Material vegetal}

El material vegetal fue adquirido en el mercado popular de la "Plaza de mercado de Paloquemao" en la ciudad de Bogotá, D.C. a partir de los reportes de Giraldo y cols. (13). Se adquirieron alrededor de 2 $\mathrm{kg}$ de material fresco de las plantas "sanguinaria”, "orozul” y "anamú". Al menos 3 ejemplares de cada especie fueron depositados en las condiciones requeridas para su identificación taxonómica en el Herbario Nacional Colombiano de la Universidad Nacional de Colombia, donde se encuentran depositados con los nombres de Lantana cámara L. (s.l.) No. COL 585817; Petiveria alliacea L. No. COL 585819 y Phyla dulcis (Trevir.) Moldenke No. COL
585816. Según identificación taxonómica anterior realizada en el Herbario de Plantas Útiles de Colombia (HPUJ), Phyla dulcis (Trevir) Moldenke y Lippia dulcis (Trevir), son nombres sinónimos de la especie Phyla scaberrima (Juss. ex Pers.) Moldenke. Para este estudio se contempló Lippia dulcis T. debido a que por lo general los reportes científicos se refieren a este género.

\section{Extracción}

El material fresco de cada planta fue llevado a proceso de secado en estufa de aire circulante manteniendo a 40 oC de 48 a 72 horas. De acuerdo con estudios etnobotánicos previos, se seleccionaron las partes aéreas de "sanguinaria" y "orozul" (hojas, flores y tallos), mientras que para "anamú" sólo se seleccionaron las hojas (24).

Los extractos vegetales se obtuvieron mediante extracción sólido-líquido (percolación) a presión atmosférica y temperatura ambiente hasta agotamiento, empleando etanol grado técnico al $96 \%$ como solvente. Para el proceso de percolación se sometieron $445.0 \mathrm{~g}$ de material vegetal seco y pulverizado de $L$. dulcis, $381.0 \mathrm{~g}$ de $P$. alliacea y $566.0 \mathrm{~g}$ de L. camara. Posteriormente, los extractos secos se obtuvieron mediante rotaevaporador a vacío, a una temperatura entre $40^{\circ} \mathrm{C}$ a $50^{\circ} \mathrm{C}$, obteniendo rendimientos del $8,15 \%, 9.30 \%$ y $9,77 \%$ para L. dulcis, L. camara y $P$. Alliacea, respectivamente, con respecto al material vegetal seco. Parte de los extractos obtenidos se reservaron para la realización de las pruebas fitoquímicas pre- 
liminares y de actividad antibacteriana y se mantuvieron refrigerados, protegidos de la humedad y la luz.

\section{Análisis fitoquímico preliminar}

A los extractos etanólicos se les realizó una caracterización fitoquímica preliminar mediante cromatografía en capa delgada (CCD) empleando placas de sílica gel 60 (Macherey Nagel ${ }^{\circledR}$ F254, 0,25 mm) y patrones de referencia: Quinidina (alcaloides), 7-hidroxicumarina (cumarinas y/o antraquinonas), $\beta$-citosterol (esteroides y/o terpenoides) y quercetina (flavonoides). Se emplearon $10.0 \mathrm{mg} / \mathrm{mL}$ para los extractos y alrededor 1.0 a $5.0 \mathrm{mg}$ para los patrones de referencia. Como fase móvil (FM) se emplearon mezclas Cloroformo:Metanol (90:10) y/o Hexano: Acetato de Etilo (60:40). Una vez eluidas, las placas se revelaron mediante luz visible y UV (a 254 y/o 365nm) y reveladores químicos universales y específicos según lo establecido por Wagner y Bladt (25). Se tuvieron también en cuenta las recomendaciones del CYTED (26). Los resultados se valoraron de forma semicuantitativa, según la apreciación subjetiva de la intensidad de color según lo propuesto por Sanabria (27): Coloración intensa: $(+++)$; coloración claramente observable: $(++)$; coloración débil $(+)$; reacción negativa y/o no se observa coloración (-).

\section{Determinación de la actividad antimicrobiana}

En el estudio fueron utilizadas las cepas Pseudomonas aeruginosa ATCC 9027, Es- cherichia coli ATCC 25922, Proteus vulgaris ATCC 6380 y Staphylococcus aureus subsp. aureus ATCC 25923, las cuales fueron proporcionadas por el cepario de la Universidad Colegio Mayor de Cundinamarca y conservadas a $-20^{\circ} \mathrm{C}$ en medio Brain Heart Infusion (BHI) con adición de glicerol al $10 \%$.

Se realizaron curvas de crecimiento de cada una de las bacterias seleccionadas, con el objetivo de establecer el tiempo de incubación necesario para alcanzar su fase exponencial de crecimiento, y definir la absorbancia correspondiente a una densidad bacteriana de $1 \times 10^{8} \mathrm{UFC} / \mathrm{ml}$. Para ello se utilizaron cultivos bacterianos en agar Mueller Hinton y se tomaron de 3 a 5 unidades formadoras de colonias (UFC), las cuales fueron transferidas a caldo Mueller Hinton. Se ajustó la suspensión al estándar 0.5 de McFarland, utilizando espectrofotometría; $y$, finalmente, se realizó la lectura de la absorbancia inicial de la suspensión a $600 \mathrm{~nm}$ y se incubó a $37^{\circ} \mathrm{C}$, realizando la lectura de la absorbancia cada hora, durante 12 horas consecutivas, teniendo en cuenta el protocolo de Cappuccino y cols., con algunas modificaciones (28). Posterior a los periodos de incubación establecidos, se determinó el recuento de unidades formadoras de colonias, para lo cual se utilizaron diluciones seriadas en agua peptonada $0.1 \%$ en un rango de 10-1 a 10-6 (28, 29). El procedimiento se realizó por duplicado y se establecieron las respectivas gráficas del crecimiento para cada cepa. 


\section{Pruebas de sensibilidad antimicrobiana}

Se realizaron antibiogramas en agar Mueller Hinton a cada una de las bacterias en estudio según las directrices del Clinical \& Laboratory Standards Institute (CLSI), a partir de cultivos bacterianos en caldo Mueller Hinton con una densidad equivalente a $1 \mathrm{x}$ $10^{8} \mathrm{UFC} / \mathrm{mL}$ (30). A partir de los ensayos se estableció como control positivo Gentamicina $(10 \mu \mathrm{g})$ y como control de negativo Dimetilsulfóxido (DMSO) al 10\%, v/v en agua estéril (31). Las pruebas con los extractos vegetales se realizaron mediante las técnicas de difusión con discos y difusión en agar.

\section{Difusión con discos}

Las pruebas de difusión con discos se desarrollaron teniendo en cuenta los protocolos propuestos por Othman y cols. (32) y Andrews y cols. (33). 24 horas previas al experimento, discos en blanco (Oxoid ${ }^{\mathrm{TM}}$ ) fueron impregnados con $20 \mu \mathrm{L}$ de cada extracto vegetal a evaluar en concentraciones de $1 \mathrm{mg} / \mathrm{mL}$ (para un primer ensayo) y $2 \mathrm{mg} /$ $\mathrm{mL}$ (para un segundo ensayo), preparados a partir de una solución stock en DMSO al $10 \%$, así como también se impregnaron discos con $20 \mu \mathrm{L}$ del control positivo y negativo. Posteriormente, se dejaron secar durante 24 horas a temperatura ambiente en condiciones de esterilidad.

Colonias de las cepas respectivas que crecieron en agar Mueller Hinton fueron seleccionadas y cultivadas en caldo Mueller
Hinton hasta alcanzar una densidad de 1 x $10^{8} \mathrm{UFC} / \mathrm{mL} \cdot 100 \mu \mathrm{L}$ de cada cultivo bacteriano equivalentes $1 \times 10^{7} \mathrm{UFC} / \mathrm{mL}$, se sembraron en agar Mueller Hinton, distribuyendo uniformemente con la ayuda de un hisopo estéril por siembra masiva y se colocaron en la superficie del medio los discos impregnados con cada extracto vegetal, un disco de control negativo y un disco de control positivo. Los medios fueron incubados a $37^{\circ} \mathrm{C}$ por 24 horas y los ensayos se realizaron por triplicado. Posterior a la incubación, se midió el diámetro del halo de inhibición del crecimiento $(\mathrm{mm})$ y se calculó el porcentaje del efecto inhibitorio relativo respecto al control positivo, aplicando la Ecuación 1:

\section{$\%$ Efecto inhibitorio = Media diámetro del halo de inhibición X 100 \\ Diámetro del halo de inhibición control Positivo}

\section{Difusión en agar}

El ensayo se llevó a cabo de acuerdo con el protocolo propuesto por Othman y cols. (32) y Cruz y cols. (34). En cada placa de agar Mueller Hinton, se realizaron cinco perforaciones (pozos) de $10 \mathrm{~mm}$ de diámetro con un sacabocados estéril y, posteriormente, cada pozo fue sellado con $0.1 \mathrm{~mL}$ del mismo agar para evitar la dispersión del extracto y los controles; $100 \mu \mathrm{L}$ de cada cepa bacteriana (con una densidad de $1 \mathrm{x}$ $10^{8} \mathrm{UFC} / \mathrm{mL}$, equivalentes a $1 \times 10^{7} \mathrm{UFC} /$ $\mathrm{mL}$ ) fueron sembrados masivamente en la superficie del medio. Se adicionó a cada pozo $20 \mu \mathrm{L}$ de cada uno de los extractos vegetales en concentraciones de $1 \mathrm{mg} / \mathrm{mL}$ 
(para el primer ensayo) y $2 \mathrm{mg} / \mathrm{mL}$ (para el segundo ensayo), preparados a partir de una solución stock en DMSO al 10\%. Se empleó un pozo para el control negativo y un pozo más para el control positivo. Las cajas se incubaron a $37^{\circ} \mathrm{C}$ por 24 horas y los ensayos se realizaron por triplicado. La actividad antibacteriana se determinó midiendo el diámetro de la zona de inhibición (mm) y se calculó del porcentaje del efecto inhibitorio relativo respecto al control positivo aplicando la Ecuación 1.

\section{Concentración Mínima Inhibitoria (CMI)}

Para determinar la CMI de los extractos que presentaron actividad antimicrobiana, se realizó la prueba de macrodilución en caldo de acuerdo con el protocolo de Abadie y cols. (35). Se emplearon cultivos bacterianos en caldo Mueller Hinton, con una densidad equivalente $1 \times 10^{8} \mathrm{UFC} / \mathrm{mL}$ a los cuales se les realizó una dilución 1/100 (1 x 1066 UFC/ $\mathrm{mL}) \mathrm{y}$, adicionalmente, se prepararon 10 tubos con $1.5 \mathrm{~mL}$ de caldo Mueller Hinton para cada prueba.

Se preparó una solución stock del extracto vegetal a una concentración de $500 \mathrm{mg} / \mathrm{mL}$ en DMSO al $10 \%$, se agregó $1.5 \mathrm{~mL}$ de la solución stock del extracto vegetal al tubo $\mathrm{N}^{\circ} 1$, el cual correspondía a la concentración de $500 \mathrm{mg} / \mathrm{mL}$. Luego, partir del tubo $\mathrm{N}^{\circ} 2$ que contenía $1.5 \mathrm{~mL}$ de caldo Mueller Hinton, se agregó $1.5 \mathrm{~mL}$ de la solución madre del extracto y se realizaron diluciones dobles seriadas hasta el tubo $\mathrm{N}^{\circ} 11$, mezclando las suspensiones con la ayuda de un vórtex y evaluando de esta manera concentraciones de $250 \mathrm{mg} / \mathrm{mL}, 125 \mathrm{mg} / \mathrm{mL}, 62.5 \mathrm{mg} /$ $\mathrm{mL}, 31,25 \mathrm{mg} / \mathrm{mL}, 15.62 \mathrm{mg} / \mathrm{mL}, 7.81 \mathrm{mg} /$ $\mathrm{mL}, 3.90 \mathrm{mg} / \mathrm{mL}, 1.95 \mathrm{mg} / \mathrm{mL}, 0.97 \mathrm{mg} / \mathrm{mL}$ y $0.48 \mathrm{mg} / \mathrm{mL}$. Posteriormente, se adicionó a cada tubo, $1.5 \mathrm{~mL}$ del inóculo preparado de cada cepa (aproximadamente $1 \times 10^{6} \mathrm{UFC} /$ $\mathrm{mL}$ ). Los tubos fueron incubados a $37^{\circ} \mathrm{C}$ durante 24 horas. Finalmente, se calculó la CMI, considerándola como la concentración correspondiente al tubo con menor concentración del extracto donde no hubo desarrollo bacteriano, demostrado por la ausencia de turbidez, para ello se utilizó un control positivo y negativo de crecimiento $(36,37)$.

\section{Concentración Mínima Bactericida (CMB)}

A partir de cada uno de los tubos sin desarrollo bacteriano visible, obtenidos en la prueba de CMI, fueron sembrados masivamente $0.1 \mathrm{~mL}$ de las suspensiones sobre la superficie de placas de agar Mueller Hinton. Posteriormente, se incubaron a $37^{\circ} \mathrm{C}$ durante 24 horas y los ensayos se realizaron por triplicado. Para determinar la CMB se realizó el recuento de colonias en las placas, considerando la concentración mínima bactericida, como la menor concentración del extracto cuyo subcultivo inhibió totalmente el crecimiento de la bacteria (35).

\section{Análisis estadístico}

Para el análisis estadístico se realizó una prueba t de Student para muestras indepen- 
dientes, con el fin de comparar el porcentaje de inhibición obtenido con respecto a las dos técnicas empleadas para la determinación de la actividad antimicrobiana, las concentraciones del extracto y a las especies evaluadas. Los valores obtenidos fueron considerados estadísticamente significativos con un valor $\mathrm{p}<0,05$.

\section{Resultados}

\section{Análisis fitoquímico preliminar}

Mediante cromatografía en capa delgada (CCD), se evidenció la presencia de metabolitos de tipo cumarina en el extracto etanólico de L. dulcis, al observarse mancha azul $(++)$ que fluoresce a la UV $(365 \mathrm{~nm})$, (Eluente: $\mathrm{CHCl}_{3}: \mathrm{MeOH}, 90: 10$, revelador químico bornträger, a $110^{\circ} \mathrm{C}$ ). En esta placa también se observan manchas y zonas rojas en los extractos etanólicos de $P$. alliacea $(++)$, L. dulcis (+) y L. cámara (+), lo que sugiere la presencia de antraquinonas. Sin embargo, se requieren pruebas adicionales para confirmarlo, como la reacción de Bornträger-Kraus. Adicionalmente, en la prueba de flavonoides se observaron a la luz visible zonas coloreadas amarillas (+) en los extractos etanólicos de P. alliacea y L. dulcis, (revelador NP/PEG 4000, eluente: $\mathrm{CHCl}_{3}$ : $\mathrm{MeOH}, 90: 10)$. Es necesario realizar pruebas de cromatografía y de coloración con extractos de mayor polaridad. Metabolitos de tipo terpenoide fueron detectados mediante vainillina/ $\mathrm{H}_{2} \mathrm{SO}_{4}$ en etanol (luz visible, a $\left.110^{\circ} \mathrm{C}\right)$, como manchas coloreadas, especialmente, violetas, cafés y azules en todos los extractos. Manchas violetas fueron intensas $(+++)$ en $P$. alliacea, mientras que manchas azules verdosas y azules fueron intensas $(+++)$ en $L$. dulcis y L. camara, respectivamente. No se observó coloración en la prueba de alcaloides (-) en ninguno de los extractos. Sin embargo, se sugiere realizar de forma completa el análisis preliminar de alcaloides según Sanabria (27).

\section{Pruebas de sensibilidad antimicrobiana}

\section{Difusión con discos y difusión en agar}

El extracto etanólico de L. dulcis presentó actividad antimicrobiana sobre $P$. vulgaris ATCC 6380 mediante difusión con discos y en agar, en concentraciones de $1 \mathrm{mg} / \mathrm{mL}$ y $2 \mathrm{mg} / \mathrm{mL}$. A una concentración de $2 \mathrm{mg} /$ $\mathrm{mL}$ mediante la técnica de difusión en agar, presentó porcentajes inhibitorios de $71.64 \%$ mientras que, a la misma concentración, utilizando discos, se establecieron efectos inhibitorios del 59.09\%, como se puede observar en la Tabla 1 . A concentración de $1 \mathrm{mg} / \mathrm{mL}$ fue también activo frente a $P$. vulgaris con porcentajes de efecto inhibitorio superiores al $50 \%$ en las dos técnicas empleadas. De acuerdo con lo establecido por Ramírez y Díaz (38), la actividad antibacteriana de los extractos se considera alta cuando el porcentaje de inhibición relativo del crecimiento es $>70 \%$, intermedia entre el 50 y $70 \%$ y baja cuando es $<50 \%$; por lo tanto, es posible afirmar que el extracto de L. dulcis presentó alta e intermedia ac- 
tividad antibacteriana respectivamente. Al evaluar los extractos obtenidos de L. camara y $P$. alliacea, no se evidenció actividad frente a $P$. vulgaris. Las pruebas anteriormente citadas contaron con un disco impregnado con DMSO al $10 \%$ como control negativo, con el cual se evidenció crecimiento del microorganismo.

Tabla 1. Actividad antibacteriana de Lippia dulcis T. sobre Proteus vulgaris ATCC 6380 por difusión con discos y difusión en agar.

\begin{tabular}{|c|c|c|c|c|c|c|c|c|c|c|c|c|c|c|}
\hline \multirow{2}{*}{\multicolumn{3}{|c|}{ TÉCNICA }} & \multicolumn{12}{|c|}{ DIÁMETRO DEL HALO DE INHIBICIÓN (mm) } \\
\hline & & & \multicolumn{6}{|c|}{ DIFUSIÓN CON DISCOS } & \multicolumn{6}{|c|}{ DIFUSIÓN EN AGAR } \\
\hline \multicolumn{3}{|c|}{ PLANTA } & \multicolumn{3}{|c|}{ Réplicas del ensayo } & \multirow[b]{2}{*}{ Promedio } & \multirow[b]{2}{*}{ D.S. } & \multirow{2}{*}{$\begin{array}{c}\text { Efecto } \\
\text { inhibitorio } \\
\%\end{array}$} & \multicolumn{3}{|c|}{ Réplicas del ensayo } & \multirow[b]{2}{*}{ Promedio } & \multirow[b]{2}{*}{ D.S. } & \multirow{2}{*}{$\begin{array}{c}\text { Efecto } \\
\text { inhibitorio } \\
\%\end{array}$} \\
\hline & & $\begin{array}{l}\text { centración } \\
\mathrm{ng} / \mathrm{mL}\end{array}$ & 1 & 2 & 3 & & & & 1 & 2 & 3 & & & \\
\hline \multirow{4}{*}{$\begin{array}{l}\text { Lippia } \\
\text { dulcis T. }\end{array}$} & & 1 & 11 & 11 & 12 & 11,66 & 0,57 & 52,23 & 14 & 13 & 13 & 13,33 & 0,57 & 55,55 \\
\hline & & 2 & 13 & 13 & 13 & 13 & 0 & 59,09 & 16 & 16 & 16 & 16 & 0 & 71,64 \\
\hline & 1 & $\begin{array}{l}\text { Control } \\
\text { positivo }\end{array}$ & 23 & 22 & 22 & 22,33 & 0,57 & N.A & 24 & 24 & 24 & 24 & 0 & N.A \\
\hline & 2 & $\begin{array}{l}\text { Control } \\
\text { positivo }\end{array}$ & 22 & 22 & 22 & 22 & 0 & N.A & 23 & 22 & 22 & 22,33 & 0,57 & N.A \\
\hline
\end{tabular}

El extracto etanólico de L. dulcis presentó actividad frente a $S$. aureus en concentraciones de $1 \mathrm{mg} / \mathrm{mL}$ y $2 \mathrm{mg} / \mathrm{mL}$. El mayor efecto inhibitorio $(64.17 \%)$, se evidenció en la técnica de difusión en agar en concentraciones de $2 \mathrm{mg} / \mathrm{mL}$, con halos promedio de $14.33 \mathrm{~mm}$ de diámetro. A concentraciones de $1 \mathrm{mg} / \mathrm{mL}$ y $2 \mathrm{mg} / \mathrm{mL}$, L cámara evidenció actividad frente a $S$. aureus, ob- teniendo su mayor porcentaje de efecto inhibitorio $(85.48 \%$ ) a $2 \mathrm{mg} / \mathrm{mL}$, en la técnica de difusión con discos. A la concentración de $1 \mathrm{mg} / \mathrm{mL}$ se evidenció actividad antibacteriana intermedia, con porcentajes de efecto inhibitorio correspondientes a $60.31 \%$ y $67.64 \%$ por difusión con disco y en agar, como se reporta en la Tabla 2. 
Tabla 2. Actividad antibacteriana de Lantana camara L. y Lippia dulcis T. sobre Staphylococcus aureus ATCC 25923 por difusión con discos y difusión en agar

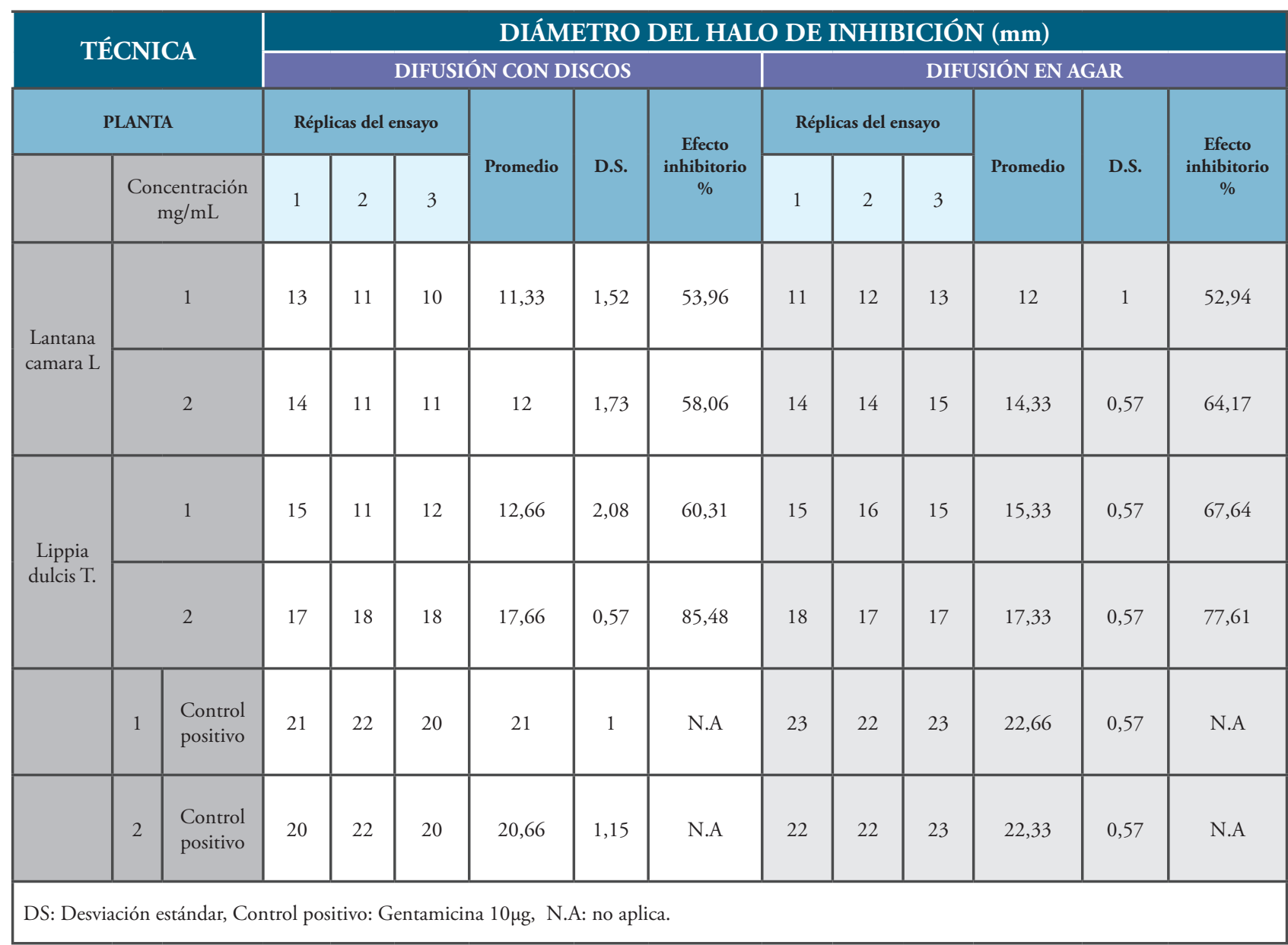

Los extractos etanólicos evaluados a concentraciones de $1 \mathrm{mg} / \mathrm{mL}$ y $2 \mathrm{mg} / \mathrm{mL}$ no presentaron actividad antimicrobiana sobre E. coli ATCC 25922 y Pseudomonas aeruginosa ATCC 9027. En cuanto al extracto obtenido de $P$. alliacea ("anamú"), este no presentó actividad frente a ninguna de las bacterias en estudio.

Al comparar el porcentaje de inhibición frente a $S$. aureus con relación a los extractos etanólicos de las especies evaluadas ( $L$. camara y $L$. dulcis) en la prueba t de Stu- dent para muestras independientes se obtuvo un valor $\mathrm{p}=0.0318$, determinando que existen diferencias estadísticamente significativas entre los porcentajes de inhibición obtenidos para cada uno de los extractos. Por otra parte, al comparar los porcentajes de inhibición entre las dos técnicas empleadas (difusión con discos y difusión en agar) mediante la prueba t de Student se encontró un valor $\mathrm{p}=0.4509$, por lo que se puede establecer que no existe diferencia significativa en los resultados de las dos técnicas. De igual manera, al comparar los porcentajes 
de inhibición obtenidos a las dos concentraciones $(1 \mathrm{mg} / \mathrm{ml}$ y $2 \mathrm{mg} / \mathrm{ml})$ no se encontró diferencia significativa $(\mathrm{p}=0.067)$.

\section{Concentración Minima Inbibitoria (CMI) y Concentración Mínima Bactericida (CMB)}

Se determinó la CMI y CMB de los extractos etanólicos obtenidos de L camara y $\mathrm{L}$. dulcis, que reportaron previamente actividad frente a algunas de las bacterias eva- luadas (ver Tabla 3). La CMI del extracto etanólico de L. camara frente a $S$. aureus, correspondió a $7.81 \mathrm{mg} / \mathrm{ml}$, donde se observó la ausencia de turbidez visible. Se observó, además, la ausencia total de crecimiento en placa a una concentración mínima de $31.25 \mathrm{mg} / \mathrm{mL}$. En relación al extracto de L. dulcis frente a $S$. aureus, presentó una CMI de $1.95 \mathrm{mg} / \mathrm{mL}$. La concentración mínima bactericida de $\mathrm{S}$. aureus correspondio a $7.81 \mathrm{mg} / \mathrm{ml}$ y $250 \mathrm{mg} / \mathrm{ml}$ para $P$. vulgaris.

Tabla 3. Concentración mínima inhibitoria (CMI) y concentración mínima bactericida (CMB) de los extractos vegetales activos frente a Staphylococcus aureus ATCC 25923 y Proteus vulgaris ATCC 6380.

\begin{tabular}{|c|c|c|c|c|c|c|}
\hline EXTRACTO & \multicolumn{4}{|c|}{ Lippia dulcis T. } & \multirow{2}{*}{\multicolumn{2}{|c|}{$\begin{array}{c}\text { Lantana camara L. } \\
\text { Staphylococcus aureus ATCC } \\
25923\end{array}$}} \\
\hline BACTERIA & \multicolumn{2}{|c|}{ Proteus vulgaris ATCC 6380} & \multicolumn{2}{|c|}{$\begin{array}{l}\text { Staphylococcus aureus ATCC } \\
25923\end{array}$} & & \\
\hline $\begin{array}{l}\text { Concentración del } \\
\text { extracto }(\mathrm{mg} / \mathrm{mL})\end{array}$ & $\begin{array}{c}\text { Turbidez } \\
\text { visible (CMI) }\end{array}$ & $\begin{array}{l}\text { Crecimiento en } \\
\text { placa (CMB) }\end{array}$ & $\begin{array}{c}\text { Turbidez } \\
\text { visible (CMI) }\end{array}$ & $\begin{array}{l}\text { Crecimiento en } \\
\text { placa (CMB) }\end{array}$ & $\begin{array}{c}\text { Turbidez } \\
\text { visible (CMI) }\end{array}$ & $\begin{array}{l}\text { Crecimiento en } \\
\text { placa (CMB) }\end{array}$ \\
\hline 500 & - & - & - & - & - & - \\
\hline 250 & - & - & - & - & - & - \\
\hline 125 & - & + & - & - & - & - \\
\hline 62,5 & - & + & - & - & - & - \\
\hline 31,25 & - & + & - & - & - & - \\
\hline 15,62 & + & + & - & - & - & + \\
\hline 7,81 & + & + & - & - & - & + \\
\hline 3,90 & + & + & - & + & + & + \\
\hline 1,95 & + & + & - & + & + & + \\
\hline 0,97 & + & + & + & + & + & + \\
\hline 0,48 & + & + & + & + & + & + \\
\hline
\end{tabular}




\section{Discusión}

La aparición de cepas resistentes a los antibióticos, elevada toxicidad, disminución del espectro de acción y los altos costos, hacen necesario el estudio de nuevos antimicrobianos de origen natural, que sean seguros, eficaces y accesibles para las comunidades $(39,40)$. En el presente trabajo, se evaluaron los extractos etanólicos obtenidos de tres especies vegetales frente a bacterias Gram positivas y Gram negativas, causantes de patologías infecciosas de importancia en salud pública.

La realización de pruebas de actividad antimicrobiana puede desarrollarse utilizando extractos vegetales obtenidos a partir de diferentes solventes de extracción como etanol, éter de petróleo, metanol, entre otros. En el presente ensayo se utilizaron extractos etanólicos debido a que pueden tener un mayor potencial antibacteriano frente a los aislamientos bacterianos en comparación con otros solventes como el éter de petróleo, gracias a su polaridad intermedia (41) y a su mayor variedad de metabolitos que le confieren esta propiedad (42).

De los tres extractos vegetales evaluados, L. dulcis presentó actividad antimicrobiana frente a bacterias Gram negativas (P. vulgaris) y Gram positivas ( $S$. aureus) y L. cama$r a$, evidenció su actividad únicamente frente a bacterias Gram positivas ( $S$. aureus). Como se reporta en estudios previos, puede haber mayor actividad por los extractos en bacterias Gram positivas, probablemente por la diferencia en la permeabilidad a los componentes activos dada la diferencia en la estructura de las bacterias Gram positivas y Gram negativas (43). Se detectó actividad inhibitoria alta para el extracto de L. dulcis frente a $S$. aureus a una concentración de $2 \mathrm{mg} / \mathrm{mL}(85,48 \%)$ mientras que los extractos de $L$. camara sobre $S$. aureus y de $L$. dulcis sobre $P$. vulgaris evidenciaron actividad inhibitoria intermedia, en concordancia con lo establecido por Ramírez y cols. (38). En relación a $L$. dulcis, en el extracto etanólico fue evidente la presencia de metabolitos tipo esteroide y/o terpenoide, (vainillina $/ \mathrm{H}_{2} \mathrm{SO}_{4}$ en etanol a $110^{\circ} \mathrm{C}$ ), los cuales podrían estar relacionados con la actividad antibacteriana observada frente a $S$. aureus y $P$. vulgaris. Cáceres y cols. (44) también confirmaron la actividad del extracto etanólico de L. dulcis frente a bacterias enteropatógenas como E. coli, Salmonella enteritidis y Shigella flexneri. Otros metabolitos detectados con una intensidad baja a intermedia en las pruebas de cromatografía fueron cumarinas (bornträger, UV $365 \mathrm{~nm}$ a $110^{\circ} \mathrm{C}$ ) y flavonoides (NP/PEG 4000); sin embargo, pruebas adicionales son requeridas para confirmarlo.

Mediante la técnica de difusión con discos, el extracto etanólico obtenido de $L$. camara presentó actividad inhibitoria frente a $S$. aureus, lo cual concuerda con lo reportado por Cruz y cols. (34), con un porcentaje de inhibición de $56.1 \%$, similar a los obtenidos en este estudio, $53.96 \%$ y $56.06 \%$ a concentraciones de $1 \mathrm{mg} / \mathrm{mL}$ y $2 \mathrm{mg} / \mathrm{mL}$, respectivamente. Adicionalmente, se repor- 
ta la ausencia de actividad frente a $E$. coli y $P$. aeruginosa, tal como lo encontrado en este estudio. En otras investigaciones, en las cuales se evaluaron extractos clorofórmicos de L. camara a diferentes concentraciones, se identificó actividad sobre $S$. aureus (45). La acción antimicrobiana de esta planta podría estar relacionada con su composición fitoquímica, constituida por sustancias con reconocida actividad antibacteriana como taninos, saponinas, flavonoides, terpenoides, antraquinonas, carotenos, alcaloides y fenoles $(46,47,48)$. Metabolitos de tipo terpenoide y/o esteroide fueron evidentes en las pruebas de cromatografía en capa delgada realizadas (vainillina/ $\mathrm{H}_{2} \mathrm{SO}_{4}$ en etanol a $110^{\circ} \mathrm{C}$ ), los cuales podrían favorecer la actividad antibacteriana frente a $S$. aureus.

Es posible que en la prueba de Bornträger se haya detectado el anilllo de quinona de las furanonaftoquinonas presentes en $L$. camara; sin embargo, son necesarios estudios adicionales. Ghisalberti (49), en su revisión, indica que triterpenos pentacíclicos (como los derivados del ácido ursónico aislados de L. camara) y las furanonaftoquinonas han demostrado actividad antibacteriana frente a bacterias Gram positivas como S. aureus. Aunque mediante cromatografía en capa delgada no fueron detectados metabolitos de tipo flavonoide en el extracto etanólico de L. camara, Naz y Bano (22) cuantificaron flavonoides totales en las hojas de esta especie por lo que estudios adicionales que empleen fracciones más polares podrían permitir su identificación. Adicionalmente, demostraron la actividad antibacteriana del extracto metanólico de L. camara frente a $S$. aureus y $P$. aeruginosa.

Es importante mencionar que el uso de etanol como disolvente orgánico, concentra mayor cantidad de compuestos afines por el agua como las saponinas y taninos. Estas sustancias presentan mecanismos de acción relacionados con la alteración de la tensión superficial de la membrana celular (50) y la inactivación de enzimas y proteínas de transporte celular (43) que pueden favorecer el efecto antibacteriano de estos compuestos.

El estudio realizado por Ochoa y cols. (51) reportó actividad antimicrobiana de extractos en solución hidroalcohólica y alcohol isopropílico provenientes de hojas de $P$. alliacea sobre $P$. aeruginosa. Sin embargo, el protocolo utilizado presenta variaciones respecto al utilizado en el presente estudio, como los solventes utilizados para la extracción, la cantidad de extracto adicionado a cada disco $(10 \mu \mathrm{L})$ y la utilización de un amplio rango de concentraciones. Adicionalmente, en el tamizaje fitoquímico de extractos hidroalcohólicos (etanol al $80 \%$ ) de hojas frescas de $P$. alliacea con acción antimicrobiana frente a $S$. aureus, $E$. coli, E. faecalis y $P$. aeruginosa, se reportó la presencia de quinonas (++ por Bornträger), alcaloides (+++ por Dragendorff) y de otros metabolitos como flavonoides, fenoles y de esteroides/triterpenos con baja intensidad. En el presente estudio, los resultados de CCD sugirieron la presencia principalmente de metabolitos de tipo antraquinona, ter- 
penoide y/o esteroide y flavonoides, estos últimos en baja intensidad; sin embargo, el extracto no demostró actividad antibacteriana. Los resultados obtenidos son coherentes con aquellos reportados por Sariego y cols., (17) quienes atribuyen la inactividad de extractos de $P$. alliacea a diferentes factores que podrían estar relacionados, como el material vegetal empleado (hojas que presenta bajas concentraciones de derivados sulfurados), la realización del secado del material, la temperatura de secado y el grado polaridad del extracto.

Los extractos etanólicos obtenidos a partir de L. camara, L. dulcis y P. alliacea no presentaron actividad sobre $E$. coli y $P$. aeruginosa. La falta de actividad de los extractos frente a estos microorganismos puede asociarse a su característica de poseer una membrana externa conformada por lipopolisacáridos, proteínas y fosfolípidos, que dificulta el acceso de los compuestos a la célula (52).

La prueba de Concentración Mínima Inhibitoria (CMI) es considerada el Gold standard para determinar la susceptibilidad de los organismos a los antimicrobianos. La determinación de la CMI por macrodilución en caldo demostró la actividad que presentan los extractos de L. camara y L. dulcis sobre $S$. aureus, a concentraciones bajas, correspondientes a $7.81 \mathrm{mg} / \mathrm{mL}$ y $1.95 \mathrm{mg} /$ $\mathrm{mL}$, respectivamente. La CMI más alta, fue $31.25 \mathrm{mg} / \mathrm{mL}$, obtenida para el extracto de L. dulcis frente a $P$. vulgaris. La sensibilidad de $S$. aureus frente a extractos etanólicos ob- tenidos a partir de L. cámara fue reportada por Cruz y cols. (34), con una CMI de $12 \mathrm{mg} / \mathrm{mL}$ por el método de macrodilución.

De acuerdo con Salada (53), la determinación de la relación $\mathrm{CMI} / \mathrm{CMB}$ permite determinar el efecto que ejerce el agente antimicrobiano sobre los microorganismos evaluados. El autor menciona que cuando el valor de $\mathrm{CMB}$ no es más de cuatro veces más alto que el de CMI, indica que el compuesto es bactericida. Según los resultados obtenidos en el presente estudio, es posible considerar que los extractos de L. camara y L. dulcis presentan actividad bactericida frente a $S$. aureus y actividad bacteriostática sobre $P$. vulgaris.

Para el estudio antimicrobiano se realizaron curvas de crecimiento bacteriano como lo establecen Othman y cols. (32), con el fin de evidenciar la cinética de cada cepa y así determinar la fase exponencial, lo que permite establecer la concentración inicial; obteniendo así, resultados con mayor grado de confiabilidad.

Los resultados obtenidos en el presente trabajo aportan información sobre la promisoria actividad antibacteriana del extracto etanólico obtenido de $L$. dulcis frente a $S$. aureus y $P$. vulgaris; así mismo, sobre la potencial acción inhibitoria del extracto de $L$. camara sobre $S$. aureus. Con este estudio, se espera promover la investigación en plantas medicinales de uso tradicional, con el fin de identificar nuevas fuentes naturales de sustancias con efecto terapéutico que podrían 
ser utilizadas para el tratamiento de enfermedades infecciosas de interés en salud pública y contribuir al estudio y uso sostenible de la biodiversidad colombiana (54-57).

Estudios bioguiados y de tamizaje fitoquímico son requeridos para confirmar los grupos de metabolitos responsables de la actividad antibacteriana de $L$. dulcis y $L$. camara. Adicionalmente, se recomienda realizar estudios con extractos hidroalcohólicos a partir de material fresco y seco (a bajas temperaturas de secado), obtenido de forma independiente tanto de hojas, como raíces y tallos de $P$. alliacea para confirmar su actividad antibacteriana y la detección de los metabolitos implicados.

\section{Agradecimientos}

Los autores expresan sus agradecimientos a la Universidad Nacional Abierta y a Distancia, a la Universidad Colegio Mayor de Cundinamarca y a la Doctora Lina Espitia.

\section{Declaración de conflicto de intereses}

Los autores declaran que no se incurrió en conflictos de intereses que hubieran podido afectar los resultados.

\section{Financiación}

Proyecto de investigación "Estudio etnofarmacológico de plantas medicinales con po- tencial actividad antimicrobiana y sobre el sistema nervioso central comercializadas en mercados populares de Bogotá, D.C." (PG-2015-003, Convocatoria 005 de 2014, Sistema de Gestión de la Investigación, UNAD).

\section{Referencias}

1. Dye C. After 2015: infectious diseases in a new era of health and development. Phil. Trans. R. Soc. B. 2014; 369(1645): 1-7

2. World Health Organization. Health statistics and information systems: Disease burden and mortality estimates, cause-specific mortality, 2000-2015. Summary tables of mortality estimates by cause, age and sex, globally and by region, 2000-2015. Global summary estimates [Internet] [Citado 20 de Enero de 2019] Disponible en http://www.who.int/healthinfo/global_burden_disease/estimates/en/index 1 . html

3. Alvo A, Téllez V, Sedano C, Fica A. Basic concepts for the rational use of antibiotics in otorhinolaryngology. Rev. Otorrinolaringol. Cir. Cabeza Cuello. 2016; 76(1): 136-147.

4. Lushniak BD. Antibiotic resistance: a public health crisis. Public Health Rep. 2014; 129(4):314-316.

5. Barrero L, Rivera S, Villalobos A. Consumo de Antibióticos en el ámbito hospitalario. Protocolo de vigilancia en salud pública. Colombia.2011 [Actualizado 29 Dic 2017; citado 01 Feb 2019]. Disponible en: http://www.dadiscartagena.gov.co/images/docs/ saludpublica/vigilancia/protocolos/p2018/pro_consumo_antibiotico_2018.pdf

6. Braz F, Monte L, Batista M, Vilar M. Milanez B. Uso indiscriminado de antibióticos e resistëncia microbiana: umareflexão no tratamento das infecçôes hospitalares. Rev. Interdisciplinar. 2011; 4(4): 72-77. 
7. Organización Mundial de la Salud. Estrategia de la OMS sobre medicina tradicional 20022005. [Internet] Ginebra, Suiza. 2002 [citado 02 Feb 2019]. Disponible en:http://apps.who.int/ iris/bitstream/10665/67314/1/WHO_EDM_ TRM_2002.1_spa.pdf

8. Instituto de Investigación de Recursos Biológicos Alexander von Humboldt. Sistema de Información sobre Biodiversidad de Colombia Biodiversidad en cifras. [Internet]. Bogotá, Colombia.2017. [citado 02 Feb 2019]. Disponible en: http://www.sibcolombia.net/web/sib/cifras

9. Bernal H, García H, Londońo C, Molano M, Quevedo G, Vásquez C. Pautas para el conocimiento, conservación y uso sostenible de las plantas medicinales nativas en Colombia. 1ra ed. [Internet] Bogotá, Colombia: Instituto de Investigación de Recursos Biológicos Alexander von Humboldt, Ministerio de ambiente Vivienda y desarrollo Territorial. 2011 [citado 03 Feb 2019].

10. Ruiters AK, Tilney PM, Van Vuuren SF, Viljoen AM, Kamatou G, Van Wyk B. The anatomy, ethnobotany, antimicrobial activity and essential oil composition of southern African species of Teucrium (Lamiaceae).S. Afr. J. Bot. 2016; 102: 175-185.

11. Pinheiro M, Cruz L, Franco J, Bittencourt R, Stefenon V. Ethnobotany and antioxidant evaluation of commercialized medicinal plants from the Brazilian Pampa. Acta Botanica Brasilica. 2016; 30(1): 47-59.

12. Savithramma N, Yugandhar P, Devi PS, Ankanna S, Suhrulatha D, Prasad KS et al. Documentation of ethnomedicinal information and antimicrobial validation of Thespesiapopulnea used by Yanadi tribe of Ganugapenta village, Chittoor district, Andhra Pradesh, India. J Intercult Ethnopharmacol. 2017; 6(2): 158-167

13. Giraldo S, Bernal MC, Morales A, Pardo A, Gamba L. Descripción del uso tradicional de planta medicinales en mercados populares de Bogotá D.C. NOVA. 2015; 13 (23): 73-80.
14. Marx HE, O'Leary N, Yuan YW, Lu-Irving P, Tank DC, Múlgura ME, et al. A molecular phylogeny and classification of Verbenaceae. Am J Bot. 2010; 97(10): 1647-1663.

15. Patel NK, Yadav RK, Bharvad PB, Ahmed AA, Mohan JS. Screening of selected aromatic plants belonging to Labiateae and Verbenaceae family for their antimicrobial activity. Discovery Phytomedicine. 2018; 5(2): 14-25.

16. Luz DA, Pinheiro AM, Silva ML., Monteiro MC, Prediger RD, Maia C, et al. Ethnobotany, phytochemistry and neuropharmacological effects of Petiveria alliacea L.(Phytolaccaceae): a review. J. ethnopharmacology. 2016; 185, 182-201.

17. Sariego S, Marin JE, Ochoa A, Viera Y. Petiveria alliacea $L$.: distintas condiciones experimentales en la elaboración de extractos con actividad antimicrobiana. Química Viva. 2013; 12(3). 274-287.

18. Mishra MP, Rath S, Swain SS, Ghosh G, Das D, Padhy RN. In vitro antibacterial activity of crude extracts of 9 selected medicinal plants against UTI causing MDR bacteria. J King Saud Univ Sci. 2017; 29(1): 84-95.

19. Marasini BP, Baral P, Aryal P, Ghimire KR, Neupane $S$, Dahal N, et al. Evaluation of Antibacterial Activity of Some Traditionally Used Medicinal Plants against Human Pathogenic Bacteria. Biomed Res Int. 2015; 2015: 1-5

20. Ulloa-Urizar G, Aguilar-Luis M, De Lama-Odría M, Camarena-Lizarzaburu J, Valle J. Antibacterial activity of five Peruvian medicinal plants against Pseudomonas aeruginosa. Asian Pac J Trop Biomed. 2015; 5(11): 928-931

21. Ochoa A, Marín J, González Z, Hidalgo A, Mujawimana $\mathrm{R}$, Tamayo $\mathrm{K}$ et al. In vitro antimicrobial activity of total extracts of the leaves of Petiveria alliacea L. (Anamu). Braz. J. Pharm. Sci. 2013; 49 (2): 241-147.

22. Naz R, Bano A. Phytochemical screening, antioxidants and antimicrobial potential of Lantana camara 
in different solvents. Asian Pac J Trop Dis. 2013; 3(6): 480-486.

23. Regnier T, Plooy W, Combrinck S, Botha B. Fungitoxicity of Lippia scaberrima essential oil and selected terpenoid components on two mango postharvest spoilage pathogens. Postharvest Biol. Technol. 2008; 48: 254-258.

24. Giraldo S, Bernal MC, Morales A, Pardo A, Gamba L. Estudio etnobotánico de plantas medicinales comercializadas en mercados populares de Bogotá, D.C. XI Simposio Argentino, XIV Simposio Latinoamericano de Farmacobotánica, I Congreso Latinoamericano de Plantas Medicinales, 2013, Dominguezia, [Resumen de memoria Ponencia] 29-30.

25. Wagner H, Bladt S. Plant drug analysis: a thin layer chromatography atlas. 2nd ed. Germany:Springer-Verlag Berlin Heidelberg New York; 1996.

26. CYTED. I curso taller iberoamericano sobre técnicas de separación e identificación de productos naturales polares organizado por las redes X.A "Red Iberoamericana de Productos Naturales de Uso Medicinal” La Laguna, Tenerife, Espańa: 2000.

27. Sanabria A. Análisis fitoquímico prelimiar, metodología y su aplicación en la evaluación de 40 plantas de la familia Compositae. Bogotá, Colombia: Universidad Nacional de Colombia; 1983.

28. Cappuccino J, Sherman N. Microbiology: a laboratory manual. 10th ed.United States of America: Pearson 10; 2014.

29. Escobar L, Rojas C, Giraldo G, Padilla L. Evaluación del crecimiento de Lactobacillus casei y producción de ácido láctico usando como sustrato el suero de leche de vacuno. Rev. Invest.Univ. Quindío. 2010; (20): 42 - 49 .

30. Cockerill FR, Wikler MA, Alder J et al. Perfomance Standars for Antimicrobial Disk Susceptibility Test - Approved Standard- Eleventh Edition. 11th ed. The United States of America: Clinical and Laboratory Standards Institute CLSI; 2012: p11-12.

31. Agrawal M, Varma A, Goyal S. Antibacterial screening of extract of the leaves of Lantana camara. Indian J. L.Sci. 2012; 1(2): 97-99.
32. Othman M, Loh H, Wiart C, Khoo T, Lim K, Ting K. Optimal methods for evaluating antimicrobial activities from plant extracts. J Microbiol Methods. 2011; 84(2):161-166.

33. Andrews J. BSAC standardized disc susceptibility testing method. J Antimicrob Chemother. 2001; 48 (1): 43-57.

34. Cruz-Carrillo A, Rodríguez N, Rodríguez C. Evaluación in vitro del efecto antibacteriano de los extractos Bidens pilosa, Lantana camara, Schinus molle y Silybum marianum. Rev. U.D.CA Act. \& Div. Cient. 2010; 13(2): 117-124.

35. Abadie RE, Medina R, Ruiz L, Tresierra-Ayala A. Actividad antibacteriana de extractos vegetales frente a cepas intrahospitalarias, Iquitos-Perú. Revista ECI Perú. 2014; 11 (1): 31-42

36. Klančnik A, Piskernik S, Jeršek B, Možina S. Evaluation of diffusion and dilution methods to determine the antibacterial activity of plant extracts. J Microbiol Methods. 2010; 81(2):121-126.

37. Clinical and Laboratory Standards Institute CLSI. Methods for Dilution Antimicrobial Susceptibility Tests for Bacteria That Grow Aerobically Approved Standard-Ninth Edition [Internet]. 2012. CLSI. Disponible en:http://shop.clsi.org/site/Sample_pdf/ M07A10_sample.pdf

38. Ramírez LS, Díaz HE. Actividad antibacteriana de extractos y fracciones del ruibarbo (Rumex conglomeratus). Scientia et Technica. 2007; 1 (33): 397-400.

39. Yılmaz Ç, Özcengiz G, Antibiotics: Pharmacokinetics, toxicity, resistance and multidrug efflux pumps. Biochem Pharmacol. 2017; 133: 43-62.

40. Shriram V, Khare T, Bhagwat R, Shukla R, Kumar V. Inhibiting Bacterial Drug Efflux Pumps via Phyto-Therapeutics to Combat Threatening Antimicrobial Resistance. Front Microbiol. 2018 Dec; 9:1-12.

41. Cowan M. Plant Products as Antimicrobial Agents. Clin Microbiol Rev. 1999; 12(4): 564-582. 
42. Corrales Ramírez L, Castillo Castañeda A, Melo Vargas A. Evaluación del potencial antibacterial in vitro de Croton lechleri frente a aislamientos bacterianos de pacientes con úlceras cutáneas. NOVA. 2013; 11 (19): 51-61.

43. Dubey, M, Sharma S, Sengar R., Bhadauria, S, Gautam R.K. In Vitro antibacterial activity of Lantana camara leaves hydrosol. J Pharm Res. 2011; 4(11): 3972- 3974.

44. Cáceres A, Fletes L, Aguilar L, Ramirez O, Figueroa L, Taracena AM et al. Plants used in Guatemala for the treatment of gastrointestinal disorders. 3. Confirmation of activity against enterobacteria of 16 plants. Journal of Ethnopharmacology. 1993; 38(1), 31-38.

45. Lingamaneni K, Rao AL, Mishra US. Antibacterial and analgesic activity of leaves of Lantana camara. International Journal of Phytomedicine. 2011; 3(3): 381-385

46. Ajiboye AA, Oyedara OO, Agboola DA, Familola OT. Evaluation of Antibacterial Effects and Phytochemical Analysis of Lantana camara linn Leaf and Berry Extracts.European J Med Plants. 2014; 4(3): 332-341.

47. Inbaraj SD, Menezes G, Josephine G, Muniappan M, Muthiah NS. Antibacterial effect of Lantana camara Linn. On Gram negative bacteria and NDM-1 strain: an in vitro study. Asian J Pharm Clin Res, 2014; 7(2): 9-12.

48. Badasa S, Bufebo T. Phytochemical screening and antibacterial activities of solvent extract of Lantana camara. L leaf from Mekelle, Ethiopia. IJP. 2015; Vol. 2(2): 77-82.

49. Ghisalberti EL. Lantana camara L. (Verbenaceae). Fitoterapia. 2000); 71(5), 467-486.

50. Aliyu AB, Musa AM, Abdullahi MS, Ibrahim MA, Tijjani MB., Aliyu, MS. et.al. Activity of saponin fraction from Anisopusmanni against some pathogenic microorganisms. J. Med. Plants Res. 2011; 5(31): 6709- 6713 .
51. Ochoa A, Marín J, Rivero D, Aguilera EM. Caracterización física, físico-química y química de extractos totales de hojas frescas de Petiveria alliacea $L$. con acción antimicrobiana. Rev. Mex. Cienc. Farm. 2013; 44 (1): 52-59.

52. Exner M, Bhattacharya S, Christiansen B, Gebel J, Goroncy-Bermes P, Hartemann P et al. Antibiotic resistance: What is so special about multidrug-resistant Gram-negative bacteria? GMS Hyg Infect Control. 2017; 12: 2-24

53. Salada J, Balala L, Vásquez E. Phytochemical and Antibacterial Studies of Lantana camara L. leaf graction and Essential oil. Inteenational Journal of Scientific and Research Publications. 2015; 5(3): $1-5$.

54. Rodríguez Pava, C., Zarate Sanabria, A., \& Sánchez Leal, L. (2017). Actividad antimicrobiana de cuatro variedades de plantas frente a patógenos de importancia clínica en Colombia. NOVA, 15(27), 119 129. https://doi.org/10.22490/24629448.1963

55. Rodríguez A, Óscar E., Roa A, V. P., \& Palacios O, Édgar A. (2017). Actividad antibacteriana y antioxidante de Baccharis revoluta Kunth. NOVA, 14(25), 57-65. https://doi.org/10.22490/24629448.1729

56. Gutierrez, D., \& Sánchez Mora, R. (2018). Tratamientos alternativos de medicina tradicional para Chlamydia trachomatis, agente causal de una infección asintomática. NOVA, 16(30), 65-74. https:// doi.org/10.22490/24629448.2836

57. Chaparro Pedraza, A., \& Campuzano, S. (2018). Aislamiento, identificación y evaluación de la actividad antimicrobiana de metabolitos producidos por Mucor circinelloides (Cepa Nativa SPG 321). NOVA, 16(29), 63-70. https://doi. org/10.22490/24629448.2690 